\title{
The Existential Imperative in Narrating Experience
}

\section{Thea Luig}

The idea that the act of narrating one's experience, in particular reorganizing disruptive experiences into a coherent story, is conducive to well-being has become popular in the social sciences and in therapeutic practice. Ways of remembering and narrating draw on templates of the larger societal, historical, and cultural context and thus situate the memory of one's particular experience within a collectively shared world. However, other voices argue that the driving force of storytelling is less the need for coherence or continuity, but rather the reconstruction of a sense of agency in intersubjective relationships. This paper will explore the question of what is at stake, what is existentially imperative, in the buman practice of narrating experience. Using a phenomenological framework that pays attention to the intersubjective space of perception and experience, I will apply narrative approaches drawing on medical anthropology, linguistics, and psychology to my conversations with Mary, a long-time caregiver for chronically ill family members.

I think it helps to find words, it helps to tell our story, it helps us to find metaphors, it helps us to make sense, it helps us to make sense ... and if you have the words that seems to open other doors, you start thinking about it in a different way, this whole concept of reframing .. I think is really important .. for caregivers .. yeah (Mary 2010, pers. comm.).

$\mathrm{M}$ ary has been taking care of chronically ill family members for 40 years. The most difficult chapter of her experience as a caregiver was the transformation of her relationship with her husband as his mental capacities slowly diminished after he suffered several strokes. After many turbulent years of requiring increasing amounts of care, Mary's husband was eventually admitted to a care institution. It had been five years since this event when Mary and I met. Through a collaboration between a University of Alberta visual anthropology course and the Alberta Caregivers Association, I was given the assignment to create a digital story episode that visualizes a caregiver's story for the association's newsletter with the goal to reduce isolation among other caregivers in Edmonton. Over the course of four visits at Mary's home, we collaboratively recorded and photographed one version of the story of her life as a caregiver.

The idea that the act of narrating one's experience, in particular putting disruptive events into a coherent story, is conducive to wellbeing has become popular in the social sciences and in therapeutic practice (Mattingly and Garro 2000, 3-4). Fundamental to this development are the writings of Jerome Bruner (1986) which conceptualize narrative as a tool that allows humans to order fragmented experience, to construct reality, and to open up a space for alternative meanings and interpretations. Such alternative potential interpretations lead to possibilities instead of certainties (Bruner 1986, quoted in Mattingly and Garro 2000, 2-3). Ways of remembering and narrating draw on templates of the larger societal, historical, and cultural context and therewith situate the memory of one's particular experience within a collectively shared world (Kirmayer, Brass, and Valaskakis 2009, 442). The socially embedded ordering aspect of storytelling is seen as having a beneficial effect on memory, perception, and experience, therefore allowing the individual to see him- or herself as continuous in time (Chandler and Lalonde 1998). An argument put forward by several authors views continuity and coherence as basic human needs. Charlotte Linde (1993), in her compelling analysis of how middle-class North Americans narrate their professional pathways, conceptualizes coherence as the creative ability to construct sufficient causality and continuity for a chain of events which then renders the experience comprehensible, meaningful, and manageable. By this process, she 
argues, people re-establish themselves as competent members of their social surroundings.

Narrative, in this perspective, is seen as an articulation of a person's sense of self; a coherent narrative reflects a sense of coherence which serves as a personal resource that enables people to persist in and cope with stressful life events (Antonovsky 1979, 1987). A growing body of research in health psychology demonstrates the positive physiological outcomes of cognitive processing by narrative integration of experience into a socially constructed image of the world and of oneself (Lepore and Smyth 2002; Pennebaker 2002).

However, there are other voices that demonstrate a lack of coherence in stories and point to the fragmented character of experience as well as narrative (Kirmayer 2000). Michael Jackson (1996, 2002) argues from a phenomenological perspective that what drives storytelling is less the need for order or continuity but rather the reconstruction of a sense of agency in intersubjective relationships.

Having a sense of agency in the intersubjective construction of past, present, and future reality is what matters to people in making meaning in their lives through actions and through communication. In narrating experience, relating to one's history and future, inter-existence and inter-experience are prior to content or form of the story. Using the account of a caregiver on how she navigated through disruption, re-shaped social roles as well as her identity, and dealt with the institutional context, I argue that negotiating inter-existence and bargaining for one's position in a contested intersubjective space of agency and legitimacy is the existential imperative in storytelling, rather than the creation of coherence in order to gain a culturally specific sense of personal continuity.

\section{INTER-EXPERIENCE, NARRATIVE, AND STORIES}

To arrive at an understanding of the existential strife of narrating experience, I will start by clarifying what is meant by experience in anthropological conceptualizing. For this purpose, I will briefly outline the concept of experience as proposed by Clifford Geertz (1973), as well as
Merleau-Ponty's (2002) perspective on the relationship between experience and perception, in order to establish the notion of inter-experience (Jackson 2002) as a fundamental assumption for my argument. Such dialogic understanding of intersubjective encounters, including interrelationships between the individual and the structural, is further supported by M.M. Bakhtin's master trope of heteroglossia which I will succinctly describe to support the argument of this paper. Drawing from these writings, I will conclude this section with an illustration of the relationships between inter-experience, narrative, and stories.

Geertz's (1973) concept of experience logically follows from his definition of culture as "webs of significances." According to him, social and cultural processes are constituted by the movement of significant symbols that "impose meaning upon experience" (Geertz 1973, 45). Perception of experience, therefore, is paralleled to an act of recognition, an identification of a phenomenon with an existing cultural signifier. Merleau-Ponty $(2001,92)$ adds another layer to Geertz's analysis by arguing that perception is "an intention of our whole being" towards relations in the world. Perception and experience are in a constant feedback loop that is given direction by relational projections which are, at the same time, temporal, social, and spatial in character. Our relations to the world, or - as Geertz would express it - the web of significances with which we situate ourselves within our sociocultural background, therefore, give perceptions meaning. Entangled in these orientations, perceptions proceed and change in a fluid dialogue with the perceiving "other." As intentionality is the driving force of relations, interrelationships, are therefore prior to the perception of experience (Jackson 1998, 3). Coherence is then part of the interpretation that is provided by the symbolic forms that traffic within social relations and which construe experience (Geertz 1973).

Avoiding dichotomizations of the personal and the social, or the private and the public, Michael Jackson $(1998,2002)$ frames this model of primacy of relations in terms of inter-est (interexistence) and inter-experience (1998, 3). This concept, which implies both Geertz's understanding 
of experience and Merleau-Ponty's phenomenology of perception, is fundamental to understanding the existential imperative in narrative. Storytelling happens at the interface of experience and narrative as well as the intersection of personal and social, and is therefore one form of inter-experience. This characteristic of verbal expression has been demonstrated from a linguistic perspective by Bakhtin (1981). His master trope of heteroglossia adds another building block towards the argument proposed in this paper.

Language, according to Bakhtin (1981), is characterized by two aspects: centrifugal and centripetal forces. The former are much stronger, ubiquitous, and account for our experience of articulated language as intrinsically particular: they stress the fragility, fluidity, and historical nature of articulations whose meanings come, change, and fade in the same way that humans come, change, and vanish. Bakhtin uses the term heteroglossia to describe the sum of the influences the particular context of any utterance has on adding to, refracting to, or subtracting from meaning. The concept of heteroglossia is extremely useful to understanding narrative since it points to the immense plurality of experience in communication between one individual and another, each being conscious at a "specific point in the history of defining itself through the choice it has made - out of all the possible existing languages available to it at that moment - of a discourse to transcribe its intention in this specific exchange" (1981, xx). The development of personhood, according to Bakhtin, can then be defined as "gradual appropriation of a specific mix of discourses that are capable of best mediating their own intentions... with a minimum of interference from the otherness constituted by pre-existing meanings (inhering in dictionaries or ideologies) and the otherness of the intentions present in the other person in the dialogue" $(1981, x x)^{1}$. Consequently, language is always meaning, always uttered to somebody else including the other of one's own inner self. Social and historical heteroglossia as well as concrete, spe- cific personal content and accent are constitutive to the centrifugal quality of language. Opposing to this, but equally implied in any articulation, are centripetal, unifying forces, which are less powerful than centrifugal ones and have a complex ontological status. The centripetal aspect of discourse pertains to the ideal of a holistic language, limiting the particularities of heteroglossia and working to allow a maximum of possible mutual understanding (Bakhtin 1981, xix). It is in this space - between the uttered word, the speaker and the environment, between centrifugal and centripetal forces, between multiple aspects of the environment - that words, speech, narrative, or stories are individualized and given shape. In this dialogic field, narrative relates to numerous other fluid socio-ideological discourses around the given topic and so becomes active in shaping dialogue. In fact, it arises out of present dialogues as a continuation and a rejoinder to them. Bakhtin $(1981,280)$ concludes that any discourse, no matter if professional, everyday, formalized storytelling, scholarly, or inner dialogue is oriented towards existing discourses, directed towards an answer, and influenced by the response it anticipates. Since such a responsive understanding, which participates in shaping discourse and articulates itself in either resistance or support, is conceptual and emotional rather than linguistic, any story or narrative will strive to meet the ontological horizon of the listener in such a way as to encounter a shared ontological background (Bakhtin 1981, 281). Bakhtin (1981, 282) goes as far as saying that the response has precedence over narrative: "primacy belongs to the response, as the activating principle... understanding comes to fruition only in the response. Understanding and response are dialectically merged and mutually condition each other." Through such dialogic encounter, differing conceptual horizons and social discourses come to interact in order to allow the speaker to get a reading on his own narrative and to enter into a dialogue between his own ontological background which determines his narrative as well as that of the listener. Therefore,

${ }^{1}$ Bakhtin uses the term language not only in the strict sense of the word but also as meaning different types of socioideological languages, discourses, and narratives. 
the arena for dialogue is not the topic of the story but rather the conceptual horizons, belief system, and ontological assumptions of speaker and listener.

At this point, after having established that perception, experience, and their articulation in language are inherently relational, construed by, and directed toward inter-est, it is now possible to explore the interaction between experience, narrative, and stories. In anthropology, the analysis of narrative as a construction of reality serves the goal to understand how people negotiate views of self and others as well as how they orient themselves along their pathways through past, present, and future. From the flow of socially mediated experience, events are selected and then "presented in an order that itself intentionally or unintentionally conveys significance" (Mattingly and Garro 2000, 260). Here is where a distinction between story and narrative becomes crucial: for the purpose of this paper, I will use the term story as comprising articulations of a sequence of actions or events which range from formalized storytelling to everyday conversations. Narrative, on the other hand, pertains to the discursive presentation of the event, the order and form given to the presentation that draws on socially significant signifiers (Culler 1981, quoted in Mattingly and Garro 2000, 12). In this view, narratives affect stories, distort content in various ways, distance the story from lived experience, and shape it according to values, forms, as well as styles shared within a group of people. Looking at narrative as distinct from story, therefore, offers an understanding of what is common within a group without disregarding the idiosyncratic aspect of a story (Mattingly and Garro 2000, 14).

According to Arthur Frank, different types of narrative made available by one's culture underlie any story and give insight into questions of ideology and institutionalized practices (1994). Charlotte Linde (1993) provides examples for this in her analysis of the narrative type of life stories as an important part of everyday discourse in North American middle class society. Within this cultural setting, constructing one's personal and professional development in a coherent life story that conforms to social expectations of continu- ity and causality is assumed to play an important role in identity shaping processes (Linde 1993). Narrative represents discourses about "normal" behaviour and feelings, and therefore about morality: about being a good person and doing the right thing. In using cultural knowledge as guidance in remembering and narrating the past, stories contribute to the maintenance of certain narratives as culturally intelligible ways of conveying experience. Following from this, the study of narrative "provides a window in the processes involved in aligning an individual's experience with one or more of these pre-existing models and how these alignments change in the light of continuing experiences and new information" (Mattingly and Garro 2000, 28). The coherence that is created in a story is less found in reality, but is rather of a fictional character, one that speaks to what matters in a certain social context. In that, stories shape conduct, behaviour, and they move to act. This points to the performative aspect of narrative; narratives can be enacted in behaviour and be seen as "unfolding personal and social drama" (Mattingly and Garro 2000, 17).

Narratives also demonstrate ways in which humans construct temporality and make sense of the past as well as the present in order to orient themselves towards the future. Jason Throop (2003, 234) identifies four different temporal orientations within experiencing and narrating: first, toward the present which consists of open possibilities in an unknown future; second, an anticipation of an imagined determined future that follows from residues of the past; third, an orientation towards the past which facilitates the construction of beginnings, middles, and ends of an experience; and fourth, the "subjunctive casting of possible futures and even possible pasts." The latter point is reflected in Portelli's (1991) argument which maintains that what is most important is that stories reveal what people intended to do instead of what they actually did. In choosing one alternative representation of a past experience over the other, people renegotiate their relationship to their history (Portelli 1991, 50). The distance that this casting of possible pasts and futures creates from lived experience is, according to Portelli $(1991,51)$, perhaps the most valu- 
able source for a better understanding of people's imagination, symbols, and desires. Stories are then always variable, partial, and unfinished. Changes in narrative might reflect changing politico-historical circumstances and self-identity. Depending on these shifts, some parts of the story might be added and others may be hidden (Portelli 1991, 53). Silence - what is not said, what is left out of a story - is just as important to consider as an intrinsic part of narrative.

In summary, I concur with Mattingly (1998, $45)$ in that lived experience is ordered by remembrance and anticipation of inter-experience, therefore already carrying the "seeds of narrative." A story then imitates experience beyond recalling mere sequences of events and, at the same time, situates the teller and his narrative negotiation of temporality and self within the symbolic, moral, and ontological context of his or her sociocultural environment. Such a perspective will facilitate the understanding of how Mary structured her account, what occurrences she emphasized, and how she eventually reconciled her experience with her notion of what it means to be a good person.

\section{NARRATING EXPERIENCE: Coherence vs. Sense of Agency}

The following section is an attempt to weave the threads of inter-experience, heteroglossia, and centripetal and centrifugal forces together in order to situate coherence and agency within narrative practice and to illuminate what matters existentially when people narrate experience. Crucial to this undertaking is a clear understanding of what is meant by coherence and continuity. At times, these terms are used interchangeably and both, or one or the other, are assumed to be universal human needs (Becker 1997; Linde 1993). Linde (1993) defines coherence as a property of a text, a logical connection of parts of the text to one another and to the text as a whole. She found the elements of continuity and causality in her analysis of life stories of North American middle-class individuals to be constitutive to coherence. Sufficient causality is established between the protagonist and the audience by providing socially acceptable reasons for and demonstrating appropriate exercise of agency in certain life choices or changes. The second element, continuity, pertains to uninterrupted successions, union, or duration of choices, characteristics, parts of one's identity, goals, or practices. Linde treats continuity as a temporal quality, the socially shared linking of past, present, and future, and therefore a matter of social knowledge.

Continuity and causality, in Linde's (1993) words, are "social expectations." Becker (1997) frames them as culture-specific "discourses of normalcy." Both of these points relate to Kirmayer's (2000) argument that the importance of coherence in a story might rather exist in the therapist's or researcher's interpretation. From this perspective, continuity and causality as culturally authorized narrative forms of remembering and storytelling may impose an order onto a story that renders it far removed from experience as lived.

As socially constructed narratives of normalcy in white middle-class North America, continuity and causality provide sufficient grounds for a story to be considered coherent, that is, to meet a shared conceptual background with the audience. In Bakhtin's (1981) terms one could say that coherence serves as centripetal force and facilitates responsive understanding. Continuity and causality are culturally specific narratives that draw on themes such as temporal linearity, individuality, productivity, and personal responsibility, all highly valued in North American society (Becker 1997). As aspects of narrative form and type, coherence and continuity are means to limit heteroglossia in the articulation of experience and are socially negotiated ways that take the anticipated response of the audience into account. The more coherent a story, the further it is from lived experience (Mattingly and Garro 2000, 36). Idiosyncratic perceptions as well as coherence are each just part of narrative heteroglossia. Since relations are prior to relating narrative towards the other, the field of intersubjectivity is what has primacy in telling one's story. After setting aside the concepts of coherence as a socially constructed tool to meet a shared ontological background with the audience and continuity as 
one example for this kind of culturally accepted narrative, I will now explore the space of interexistence for its potential answers to the question of the existential imperative of narrating experience.

Humans become persons by acting and being acted upon. Personhood consists of a process "to negotiate, reconcile, balance, or mediate these antithetical potentialities of being, such that no one person or group ever arrogates agency so completely and permanently to itself that another is reduced to the status of a mere thing, a cipher, an object, an anonymous creature of blind fate" (Jackson 2002, 13). Bracketing the unresolved question of whether there is actual human choice, it is Jackson's notion of a sense of agency, in the meaning of having a say in one's life and an effect on the context beyond the individual, that I will adopt for the purpose of my argument. According to Jackson (2002, 14-15), maintaining a sense of agency is the existential imperative within every intersubjective encounter. He transfers this model to the dialogic process of storytelling: the reworking of events and sensemaking of disruption through dialogue with others are equally dependent on shared imperatives and values. Jackson's main argument is that what drives storytelling is less the need for order or continuity but rather the reconstruction of a sense of agency. According to him, a universal human preoccupation is to be in control, in some meaningful way or another, over one's lifeworld: "nothingness is, accordingly, the dispossession of choice" (Jackson 1998, 17). He argues that intersubjectivity consists of a constant negotiation between the world one feels in control of and the world of the other to which one has to adjust one's own to. Power and control, therefore, are not only systemic patterns that influence local lives in various ways, but are first and foremost existential tasks that are worked out in everyday interaction (Jackson 1998, 19-20). If the overwhelming control of others leaves a person unable to act, then according to Jackson (2005, 94-107), the individual will engage in various activities to objectify this loss of agility in order to recreate a sense of ability to act and manage the world. Storytelling as an intersubjective encoun- ter is one way of reconstructing this sense of having a say in one's life.

This view is supported by Kirmayer (2000) who emphasizes the renegotiation of power and legitimacy in narrative, as well as by Frank, who argues that the decisive tension in illness narrative is the struggle to sustain one's voice, "a self-conscious effort to bold her own against the forces that threaten to overpower her voice and her text" (Frank 1994, 4-5, original emphasis). In their argument, these writers focus on illness narrative and therewith lead us from the general interests in what is at stake in narrating experience to the more specific topic of disruptive life events. Illness that affects oneself or a closely related person disrupts expectations, goals, routines, and fundamental assumptions of one's being in the world. Chronic illness that requires a renegotiation of social roles and identities is especially a disturbance of the taken-for-granted world of everyday life that requires the revision of plans, goals, and images of self and the world. Pellegrino (1979, quoted in Mattingly and Garro 2000, 28) fittingly coins such incidences an "ontological assault." In the face of such uncertainty and open-ended redefinition processes, desire plays an important role. As Mattingly $(1998,93)$ writes: "We act in order to bring certain endings about, to realize certain futures, and to avoid others." The negotiation of agency and legitimacy, of a sense of having a say in one's life is fundamental to this process. Storytelling within culturally informed frameworks of knowledge, authority, and morality serves to legitimate, challenge, or affect shifts in the construal of interrelationships between socially positioned agents (Mattingly 1998, 154).

However, the inner experience of affected people in acute disruptive situations is rather fragmented (Kirmayer 2000; Mattingly 1998; Mattingly and Garro 2000). As Kirmayer (2000, 174) explains, articulations of illness experience are "fragmented and contradictory, taking the form of potential stories or tentative metaphors." In the encounter of patients, caregivers, and the medical system, dialogue often consists rather of contested metaphors that negotiate conceptual models, legitimate knowledge, and relative social 
positions of participating actors: "The politics of metaphor inheres in the processes that authorize and control interpretations" (Kirmayer 1992, 340). The prominence of metaphors, as well as the decisive influence of the institutional landscape, from which metaphors and narrative arise (Saris 1995), will play a crucial role in understanding what is at stake in Mary's story of her experience taking care of her chronically ill husband.

\section{FINDING WORDS}

Applying this theoretical focus on dialectic and political processes in the space of interexperience inherent in any dialogue, it appears inevitable to make the intersection of Mary's account with my life explicit and to write this section as my hearing of her story (Sarris 1993). The occasion for our encounter was given by an assignment for a course on visual anthropology in collaboration with the Alberta Caregivers Association. The organization wanted a visualization of the story of one caregiver in order for other caregivers to feel less isolated with their own experiences. Mary was selected by the association and agreed to participate. At this time, she had not been actively taking care of someone in her home as her handicapped children were more or less independent and her husband had been admitted to a care institution five years earlier. This assignment confronted me at a point in my research where I was interested in the positive effects of storytelling on psychological and physical health and how the narrative restructuring of the memory of an experience changes its perception and subsequently transforms one's self-representation.

As stories are told in response to the anticipated understanding of the audience, shaped by the particularities of the encounter between individuals at specific points in their personal history, and are part of continuous and unfinished meaning-making in inter-experience, my account is a reflection of this chance encounter at the intersection of two unfolding pathways of making sense of life. I will situate my learning of Mary's stories within the theoretical discussion above in an attempt to explore the question of what matters in exchanging stories.
When I visited Mary for the first time, I had several interview questions prepared that aimed to elicit her life story, to explain how things came to be the way they were, how she made decisions, how her social relationships were affected, and how she feels about her life in the present when looking back at past challenges and difficulties. However, it needed only one initial question for our conversation to take on an informal, pleasant, mutually interested character that centered on certain themes instead of following a chronological course of events. At first, her caregiving revolved around her autistic and schizophrenic daughter as well as her adopted son with Fetal Alcohol Syndrome. In addition, Mary's parents required care as her mother developed Alzheimer's and her father had to undergo the amputation of one leg. The most significant changes in her life, however, were brought about through the several strokes that her husband suffered and that diminished his ability to make sound judgments.

While going through the purpose and procedure of the project and explaining the consent form, Mary immediately asked who the audience of the story would be. Upon learning that it was intended for other caregivers, she herself set the stage for everything that followed and conceptualized the encounter as a sharing circle: the respectful and free expression of one's experience and emotions to a supportive group of people who share a common situation, goal, or challenge. With this in mind she emphasized the difficulties of caregiving and how she was able to overcome them. The importance of language and narrative in going through illness experiences in close relationships emerged clearly from the first interview. Mary felt that the subtle but profound changes in the relationship with her husband deprived her for a long time of the ability to make sense of and to communicate her experience. During the course of three interviews, in which Mary's interpretations often met with my interest in processes of narrative transformation and sense of control, two focal points emerged in our dialogue: first, the transformation of perception through words, or narrative, as well as the transformation of words and narrative through experience; second, the difficulty 
to negotiate situations when a profound lack of control, decision-making authority, and autonomy is felt. When I expressed my impression of these two themes being central in her story, she confirmed without hesitation and agreed to let the three-minute digital visual story we were to produce for the Caregivers Association revolve around the concepts of "words" and "control."

Due to the scope of this essay, my discussion will be selective and although the material certainly allows for a more comprehensive analysis, I will neither explicitly focus on time or memory nor on the narrative reflection of her immigrant family history or her educational background. Since Mary was not concerned with establishing chronology in our conversations but remembered events or thoughts according to themes, I will, for the purpose of the analysis here, group parts of her interview together as they illustrate the predominance of metaphors, heteroglossia, and sense of agency.

According to Merleau-Ponty (2002) the way we relate to the world gives our perceptions meaning. Bodily perception therefore cannot be separated from experience, meaning, and relational projects with the surrounding world. Kirmayer (1992, 325) explains that for understanding experience, the body as a "vehicle for thinking, feeling, and acting" needs to be considered. Metaphors are grounded and restricted by the bodily experience and social regulations that order sensorimotor processes. They assign the properties of one phenomenon on another "and all of our cognitive, affective, and somatic ways of knowing may be brought to bear to elaborate metaphoric correspondences" (Kirmayer 1992, 332). This embodied knowing serves to process complex and abstract experiences, to mediate the immediate (Kirmayer 1992, 336), and to articulate disruptive experiences. Mary extensively uses metaphors. One expression immediately caught my interest for its physical immediacy and which seemed to summarize her perception of the time of acute care giving: "being right up against the glass."

Author (A): So, you said it was really hard to put into words what was happening. Have you since found words that can stand as a metaphor for what that period was like?

Mary (M): That's getting much easier and it's that capacity in me that seemed to be totally diminished .. It was as if you were right up against the glass [she puts her hands close in front of her face] all the time and I couldn't get any perspective and I think I couldn't get any perspective to find words to find metaphors .. You know, I was just thinking this morning when you were talking about this project, it's a very tired metaphor, but caregiving really is akin to a river and there is times when it's quite pleasant and life seems pretty normal and then you hit the rapids.

In this paraphrase, two time frames are collapsed: the memory of the past fragmented experience of being faced with threatening illness episodes of her husband, rapid changes in his mental capacities and consequently their relationship, as well as the various demands of the medical bureaucracy. In these situations she remembers neither being able to see herself and what was happening in context nor being able to communicate this experience. Immediately following this metaphor she articulates that in retrospect she does find a metaphor that expresses continuity while simultaneously including unexpected, disruptive events: a river with rapids. In revising her memory she situates events along the mental representation of a continuously flowing river, the banks and direction of which are not visible to one caught in the rapids. However, she calls the metaphor "tired," meaning that although it meets a widely shared conceptual background, its common usage has deprived it of much personal, particular meaning and removed it, for Mary, from lived experience.

The state of standing too close against a glass pane is not only physically constricting, but also visually, in that it reflects one's own image in a way that blocks the view onto the larger part of oneself as well as onto one's surroundings and whatever is behind the glass. Another quality of this metaphor is the separation it illustrates: standing against a glass pane separates oneself from others and leaves one unable to communi- 
cate. Physical, visual, and communicative restrictions contained in this metaphor allow the listener to comprehend the limited agency that Mary experienced during her husband's illness. In that, "right up against the glass" and the analogy of the river with rapids are both metaphors that rely on common knowledge of physical phenomena. The former represents more centrifugal aspects but reveals more of Mary's particular experience, while the latter acts as centripetal force but leaves the metaphor removed from lived experience.

Another metaphor she uses is opening doors, which signifies the more or less sudden ability to reconstruct oneself and one's life in a way that allows alternative perceptive and behavioural possibilities.

A: So the support group or other people's experience help to find words?

M: I think it helps to find words, it helps to tell our story, it helps us to find metaphors, it helps us to make sense, it helps us to make sense ... and if you have the words that seem to open other doors, you start thinking about it in a different way, this whole concept of reframing .. I think is really important .. for caregivers .. yeah.

Mary's assessment of the role of communicating experience to others exemplifies what Garro (2003, 35) describes as "moving from the indeterminacy of culturally informed experience to culturally grounded accounts of interpretative possibilities." The kinaesthetic possibilities that opening doors offer directly translate into regained agency provided by the metaphorical transformation of experience. In Kirmayer's (2004) research on metaphoric transformation in healing practices, he situates the mediating level between the social context and physiological outcomes within the higher cortical functions of language and imagery. A switch in meaning arrived at by a change in metaphorical representation yields a transformation of perception and experience. Medical labels can fulfill a similar function and be seen as metaphors of such transformative powers as becomes clear in Mary's account:
M: I think the first time I saw the word 'dementia' on a .. assessment of my husband... and this was part of this internal process of reidentifying myself as a caregiver rather than a wife because .. because judgement issues .. ah .. I'll tell you a little anecdote: he decided, my husband Tom $^{2}$ decided that he wanted a scooter and I said I'll look into it, I'll talk to the doctor, I'll see if we can get funding, you know all the logical things to do, I said when I finish work, that would have been in April. One day I came home and the telephone book was open and it was the page for taxis and my husband wasn't home and just about then, a taxi drove up and my husband got out of the taxi, he was in his pyjamas, his housecoat and his slippers and he had gone to a medical store and they had sold him a scooter and .. you know .. now, I would have handled it totally different, I would have taken it back, I would have said this is crazy, this cannot be, but then you know I was in that zone, where I was still trying to negotiate, the way you negotiate with your husband, so he got the scooter home and he had it for about a year and it was just a disaster, he'd run off and you know two miles later he'd run out of gas and I'd have to go and get him [laughs] and get the scooter, I mean it was so

\section{A: when the word dementia}

M:

that changed

things for me because that's when I thought ok, ok c'mon, this is real, you, you, you and it certified .. seemed to certify for me that in fact it was no longer possible, that I was responsible for these judgements and I had to take the control that was very difficult because it led to a lot of conflict.

This passage contains the account of redefining narrative and of a transformation of identity on multiple levels. "Dementia" as an illness label transports meanings that are legitimized by the socially and ontologically authorized medical system. This authority has the force to shape the perception of Mary's daily interaction with

${ }^{2}$ Name changed. 
her husband and to restructure their respective positions within their relationship. It provides meaning and explanation to phenomena that did not match her previous experience and were therefore hindering her from incorporating them into the view of herself in the future and from taking action towards it. The account suggests that Mary had the possibility to draw on various potential interpretations each stemming from a different framework of moral knowledge. However, only socially authoritative knowledge "certified" that her inability to maintain her role as spouse in the way she was used to was caused by a "real" change in context. This resolves the situation's moral dilemma of reconciling the erratic acts of her husband with being a morally attuned wife who, in her social context, would respect her husband's decisions and judgements. The medical assessment of her husband's diminished judgement abilities legitimized her change in social roles and gave meaning to the conflict that arose between the spouses while approving her moral flawlessness. Social approval of a shift in self-identity restores agency which was missing before the label dementia transformed and confirmed her perception. The redefinition of herself as a caregiver, someone who takes responsibility over another person with whom she before had an equitable relationship, was the most disruptive element in her experience. What it means to be a mother as opposed to a wife entails embodied normative knowledge that, to effect its re-consideration, requires an authority that is above socially expected family roles. Professional medical discourse in Mary's sociopolitical context has the status to be this legitimizing force. Medical narrative as well as moral issues on appropriate family and gender roles therefore are continuously intertwined in Mary's experience, way of remembering, and shaping her story.

The method of "reframing" is used in therapeutic practice to transform emotions, which are based on socially learned perceptions and interpretations potentially inhibiting constructive action in the face of chaotic events, into morally sound emotions that open up space for agency
(Kirmayer 2000, 154). In Mary's case, the substitution of the word "guilt" with the term "regret" allowed her to again see herself as a good person who is doing the right thing:

M: Ms. Arnold $^{3}$ is a psychologist in town and she's on the Caregivers Association and she developed a presentation called 'reframing guilt' and that is very helpful and see there's the words, you know, we speak of it as guilt, but for her better words are regret, sadness: I regret I cannot, so rather than feel guilty that I can't keep my husband at home, I regret, I am really so sad, sorry, so sorry I can't keep my husband, but I can't and it's not, it's not so much guilt as regret, I found that very helpful.

This transformation from guilt to regret is an interesting move. It allowed Mary to feel morally at ease, to accept her emotional state, and to feel legitimized in her decision to give her husband into a care institution.

It becomes clear how Mary's particular experience is articulated using various socially and culturally based narratives that strive for a shared ontological horizon and allow her to re-situate herself as a morally sound member of her social environment. Multiple voices such as socially grounded family and gender narratives, medical discourses, moral questions, and professional knowledge are combined in fragments of her continuing and partial stories that work to restore her sense of having a say in past, present, and future inter-experience.

On other occasions, professional discourses of transforming experience into socially acceptable articulations did not strengthen her sense of agency but provoked her resistance, as she perceived them as attacks on her power to make decisions:

M: I think there is some pressure to be upbeat, to be .. in control .. you know .. and, and .. you're not always

A: There is a trend in psychology on benefit finding

M: $\quad$ Benefit finding?!! Oh wow ...

\footnotetext{
${ }^{3}$ Name changed.
} 
That's right! And if you're not feeling the benefit there's something wrong with you. You're not in a terrible situation, we don't have to look out for you, you just got to be stronger. Yes! Absolutely, absolutely, so .. allowing people .. just sitting with people in those really dark times .. I think is critical and not discounting that .. where do we get the idea there's benefit in everything? [laughs] .. is that that learned optimism of American psychology? [Laughs.] But that's the ideal, it's not always possible, we're humans, I don't think ... there's a German poet - Rilke? (A: yeah, Rilke) he says: we waste our sorrows. And I remember that re:ally stayed with me: we waste .. our sorrows

\section{A: I don't quite understand.}

M: Well, I think he's saying, I mean ironically, maybe he's saying there's benefit in sorrow, but first of all you have to accept, acknowledge sorrow.

This episode shows how institutional discourse and practice privileges certain narratives, defines and constitutes, as well as silences and erases articulations depending on socially admissible boundaries (Saris 1995, 42). The social demand to be a positive, self-reliant, and wellfunctioning member of society which is directed at the caregivers in this program is explicit in the institutional attempt to transform grief into challenge and self-development. It also demonstrates how coherence and continuity might rather exist in social-normative, authoritative, or academic interpretations instead of in an individual's experience. Mary formulates her critique of prescriptive professional narratives by using an alternative form of socially valued knowledge: the poetry of Rainer Maria Rilke (1923). By attaching legitimacy to the narrative of the poet, Mary is able to restore her agency to make decisions about right and wrong emotions, even if they are opposed to authoritative discourses.

The following extracts from Mary's account will further clarify the existential role that agency, or rather the lack of agency, plays in inter-experience.

M: In nine .. in two thousand and two, I really felt my husband should go into care, he had had another stroke, he had another stroke and broken his leg and he'd been in the Glenrose for months and I did not want him to come home, I was very aware of that and I, I told the medical staff that I felt .. he would fall at home and he was a big man and I couldn't lift him and he would fall at night, I was, it seemed to me it was dangerous and it was very difficult for both of us, but they said, the decision as no he would remain at home and then he had another stroke in two thousand three or four and he was admitted to this Choice program which was a day program which was a tremendous help for me, I can't say enough of that program and then in two thousand and five he had another stroke and at that time it was decided to put him into care and the doctor who had made the first decision to send him home, apologized and said they had made the wrong decision

A: it was three years

M: It was three years and it was, it was very tough and I still think it was the wrong decision and, and .. I felt so: powerless at that point.

In this account, Mary describes the contest between power and legitimacy that she had to engage in while interacting with medical bureaucracy. The narrative of her experience is constituted by the entangled memory of exhaustion, her interpretation of the doctor's narrative, and her knowledge of the contested nature of discourse within the medical system, which in concert results in her questioning the legitimacy of the medical system and in criticizing its authority. The feeling of having no say in the decision that would affect her and her husband existentially is of fundamental importance in remembering this episode. To counter this remembered lack of agency, Mary openly examines the validity of the medical decision and provides evidence that establishes it as morally and factually wrong.

Apart from the institutional setting, institutions of gender roles and marriage are equally at stake when agency and legitimacy are negotiated in narratives of disruptive events. In the follow- 
ing, Mary elaborates on the importance that the need for control takes on in situations when it is increasingly contested:

M: With my husband, I found that change very gradual, and partially I think it was because of my husband's personality, he was very gregarious, outgoing, sometimes demanding person and so .. there was always this .. negotiation, cause I think .. as he lost more and more control, I think, this is probably quite true for all of us, he wanted more and more control. So that was a hard part and I didn't want to give up marriage, didn't want to give up being his, his partner, you know, didn't want to give that up.

A: That's another interesting point, losing control is not only an issue for the caregiver but also for the patient

M:

Oh, absolutely! Absolutely. And the way you thought world worked ... Tom was nineteen years older than I, had pretty traditional ideas about, you know .. the roles of men and women .. and ... uhum .. absolutely, that's what, I think, makes it so difficult, you got two people who don't know exactly where they're standing.

A: And he tried to somehow substitute for the loss of control and exercise control in other places?

M: Well, he wanted control over his life, he never took instructions easily [laughs] part of this stories certainly overlap but part of them, part of the story is unique depending on the personalities and the situation so..

A: Did you find something to substitute, in another area...

M: I enjoyed my work immensely .. and .. certainly in the last twenty years it was a sanity saver .. it was, it really, really was .. the ability to walk into class where I did get to make the choices, I did have the authority [smiles] .. ahm .. I could reap the rewards of what I planned and set into operation ... Well, teaching! Teaching! That was just a god-send, because ... I think, control is a fraught word, because I think it has a negative connotation, so I'm not entire ... I'm trying to think whether another .. confidence or .. I don't know, but you know what I mean

A: also maybe

autonomy

M: $\quad$ and that's what I had at work! I had a job that really allowed me autonomy.

What is particularly interesting in this part is that the term "control" and the rather negative meaning commonly associated with it do not correspond to Mary's understanding, and she actively searches for a better word. Again, this met with a concern of my own, and consequently we tried to think of a term that would express the particular meaning we both shared. In addition to "control," "confidence," and "autonomy," we also briefly discussed, but then dropped, "selfdirection." Based on what I have learned from Mary's account, I suggest that Jackson's notion of sense of agency, of having a say in one's life, comprises all four of the above suggested concepts and articulates what is imperative in Mary's and her husband's experience. Mary's "sanity saver" was having autonomy, getting "to make the choices" in her position as a teacher; in other words, the maintenance of a sense of agency is what matters existentially in intersubjective encounters and this is reflected in the process of narrating experience.

Articulating the fragments of experience and engaging in the intersubjective field of negotiating legitimate knowledge and roles opens up alternative possibilities that restore a sense of playing a part in one's own life, of having a say in one or the other area of inter-existence. As Mary's story shows, a dialectic interaction of a multitude of voices of differentially positioned social actors has to be considered constitutive to this process.

\section{CONCLUSION}

M: I think, in fact, we're making the story all along the way, cause that's what I was doing when I was talking to friends and talking to my sister, you know you're really telling the story. It's not a story in that .. you know in literature stories have an end, we don't have a real end, we 
at least construct this closure whereas you don't have that but, uhm, I think the storytelling goes on all the time and I doubt, I can't imagine ever being satisfied with one version of the story [laughs] ... it still goes on.

Mary's continual reconstruction of the way she remembers her time as a caregiver illustrates the existential imperative toward restoring a sense of control and a sense of agency in the narration of experiences that are perceived as disrupting one's taken-for-granted understanding of the world. Her story reflects a continuing negotiation of voice and legitimacy in the intersubjective space in which experience and its articulation unfold. The tug-of-war of centrifugal and centripetal forces constitutes her striving to find metaphors that simultaneously express the particularity of her experience and meet a responsive understanding of the listener, as well as to restore the fit between her actions with her self-identification with an ethics of being a good person.

What I hope to have shown in this paper is that for the understanding of what is at stake when people articulate their experiences is perhaps less the content and the ordering of events in the story, but rather what is acheived for one's sense of agency and one's ethical legitimacy in relation to others within the space of inter-existence.

$\begin{array}{ll} & \text { Notes on Transcription } \\ {[\text { ] }} & \text { non-verbal articulations } \\ , & \text { short pause } \\ . . & \text { medium pause } \\ \ldots & \text { long pause } \\ : & \text { extended vocalization } \\ \text {. } & \text { stop } \\ \text { Speech } & \end{array}$

overlapping speech continued speech

\section{ACKNowledgments}

This paper was prepared for Dr. Andie Palmer's ANTHR 589 course, Oral History: Seminar on Life Story Methods. The project that the paper is based on consisted of a digital story prepared for ANTHR 524: Visual Anthropology, with Dr. Christopher Fletcher and for the Alberta Caregiver Association. I am deeply grateful for the contributions of Mary and her late husband. Mary's openness in sharing her story, her insightful reflections, her willingness to experiment with visual expression, the time and effort she invested in verifying the accuracy of what was presented of her story, her permission to submit this paper to Diversipede, and finally but most importantly her friendship, made this paper possible. I am also thankful to the Alberta Caregiver Association and Community Service Learning for the opportunity to realize this project.

\section{ReFERENCES Cited}

Antonovsky, Anton. 1979. Health, Stress, and Coping. San Francisco: Jossey-Bass Publishers. 2. 1987. Unraveling the Mystery of Health. How People Manage Stress and Stay Well. San Francisco: Jossey-Bass Publishers.

Bakhtin, Mikhail M. 1981. The Dialogic Imagination: Four Essays. Edited by Michael Holquist. Translated by Caryl Emerson and Michael Holquist. Austin: University of Texas Press.

Becker, Gay. 1997. Disrupted Lives: How People Create Meaning in a Chaotic World. Berkely, Los Angeles: University of California Press.

Denham, Aaron R. 2008. "Rethinking Historical Trauma: Narratives of Resilience." Transcultural Psychiatry 45: 391-414.

Frank, Arthur W. 1994. "Reclaiming an Orphan Genre: The Fist-Person Narrative of Illness." Literature and Medicine 13 (1): 1-21.

Garro, Linda C. 2003. "Narrating Troubling Experience." Transcultural Psychiatry 40: 5-43.

Geertz, Clifford. 1973. The Interpretation of Cultures: Selected Essays. New York: Basic.

Jackson, Michael. 1996. Things as They Are: New Directions in Phenomenological Anthropology. Bloomington: Indiana University Press. 1998. Minima Ethnographica: Intersubjectivity and the Anthropological Project. Chicago: University of Chicago Press. 2002. The Politics of Storytelling: Violence, Transgression, and Intersubjectivity. Copenhagen: Museum Tusculanum Press. 2005. Existential Anthropology. Events, Ex- 
igencies and Effects. New York: Berghahn Books. Kirmayer, Laurence J. 1992. “The Body's Insistence on Meaning: Metaphor as Presentation and Representation in Illness Experience." Medical Anthropology Quarterly 6 (4): 323-346. 2000. "Broken Narratives: Clinical Encounters and the Poetics of Illness Experience." In Narrative and the Cultural Construction of Illness and Healing, edited by Cheryl Mattingly and Linda C. Garro. Berkeley: University of California Press.

. 2004. "The Cultural Diversity of Healing: Meaning, Metaphor and Mechanism." British Medical Bulletin 69: 33-48.

Linde, Charlotte. 1993. Life Stories. The Creation of Coherence. Oxford: Oxford University Press. Lepore, Stephen J., and Joshua M. Smyth. 2002. The Writing Cure: How Expressive Writing Promotes Health and Emotional Well-being. Washington, D.C.: American Psychological Association.

Mattingly, Cheryl. 1998. Healing Dramas and Clinical Plots. The Narrative Structure of Experience. Cambridge: Cambridge University Press.

Mattingly, Cheryl and Linda C. Garro, eds. 2000. Narrative and the Cultural Construction of Illness and Healing. Berkeley: University of California Press.

Merleau-Ponty, Maurice. 2002. Phenomenology of Perception. Translated by C. Smith. London and New York: Routledge.

Pennebaker, James W. 2002. Emotion, Disclosure \& Health. Washington, D.C.: American Psychological Association.

Portelli, Alessandro. 1991. The Death of Luigi Trastulli and Other Stories: Form and Meaning in Oral History. Albany: State University of New York Press.

Rilke, Rainer Maria. 1923. Duineser Elegien. Leipzig: Insel-Verlag.

SAris, Jamie A. 1995. “Telling Stories: Life History, Illness Narratives, and Institutional Landscapes." Culture, Medicine, and Psychiatry 19: 3972.

SArris, Greg. 1993. Keeping Slug Woman Alive: A Holistic Approach to American Indian Texts. Berkeley: University of California Press.

Throop, Jason C. 2003. "Articulating Experi- ence." Anthropological Theory 3: 219-241. 